\title{
Fluorocarbon impurities in KrF lasers
}

\author{
Helen H. Hwang, Kristopher James, Roger Hui, and Mark J. Kushnera) \\ University of Illinois, Department of Electrical and Computer Engineering, $1406 \mathrm{~W}$. Green Street, \\ Urbana, Illinois 61801
}

(Received 24 January 1991; accepted for publication 7 March 1991)

\begin{abstract}
Fluorocarbon impurities are known to have deleterious effects on the operation of excimer lasers; however, the sensitivity limits are poorly known. Absorption at $248.9 \mathrm{~nm}$ in an $e$-beam-pumped $\mathrm{KrF}$ laser has been attributed to $\mathrm{CF}_{2}$, produced by plasma fragmentation of precursor molecules such as $\mathrm{CF}_{4}$. In this paper, the effects of $\mathrm{CF}_{4}$ impurities on the gain of an electron-beam-excited $\mathrm{KrF}$ laser are investigated theoretically. It is found that the density of $\mathrm{KrF}(B)$ significantly decreases and absorption increases when the $\mathrm{CF}_{4}$ concentration exceeds $0.03 \%$. The decrease in the density of $\mathrm{KrF}(B)$ is dominantly the result of the interception of precursors to forming the upper laser level, as opposed to direct quenching.
\end{abstract}

\section{INTRODUCTION}

The performance of electron-beam- (e-beam) and discharge-excited excimer lasers is known to be sensitive to trace impurities. ${ }^{1}$ These contaminants are present in the feedstock gases, are generated by plasma decomposition of other innocuous impurities or by the decomposition of the feedstock gases themselves. ${ }^{2,3}$ Laser efficiency was measured by Kimura and Seamans in an $e$-beam-excited XeF laser during controlled impurity addition. ${ }^{4}$ They observed a monotonic and nearly linear decrease in laser efficiency upon addition of $\mathrm{CF}_{4}, \mathrm{O}_{2}, \mathrm{HF}, \mathrm{CO}_{2}, \mathrm{CO}$, and $\mathrm{SiH}_{4}$. An addition of $0.1 \% \mathrm{CO}$ was sufficient to extinguish the laser while an addition of the same amount of $\mathrm{CF}_{4}$ decreased laser efficiency by $25 \%-30 \%$. Mandl and Hyman attributed the superior performance of repetitively pulsed $\mathrm{XeF}$ lasers in mixtures using $\mathrm{F}_{2}$ compared to $\mathrm{NF}_{3}$ to buildup of $\mathrm{N}_{2}$ by plasma decomposition of $\mathrm{NF}_{3}{ }^{2}{ }^{2}$ They hypothesized that charge exchange of $\mathrm{N}_{2}$ with $\mathrm{Ne}_{2}^{+}$forming $\mathrm{N}_{2}^{+}(X, v=3,4)$ resulted in absorption at the laser wavelength $(\lambda=351 \mathrm{~nm})$.

ArF and $\mathrm{KrF}$ excimer lasers also have shown unexpected sensitivity of small amounts of impurities, and fluorocarbons in particular. ${ }^{1}$ Fluorocarbons such as $\mathrm{CF}_{4}$ are common contaminants in the feedstock halogen gases (most often $\mathrm{F}_{2}$ ), or are generated in situ from reactions of fluorine with organic contaminants resulting from sealants, solvents, or pump oils. The origin of the sensitivity of $e$-beam-excited $\mathrm{KrF}$ lasers to this contamination is not clear. It is known that reactions of $\mathrm{Kr}^{*}$ with $\mathrm{CF}_{4}$ molecules most often quench $\mathrm{Kr}^{*}$ as opposed to resulting in the harpooning reaction leading to excitation of the upper laser level as occurs with $\mathrm{F}_{2} .{ }^{5}$ Therefore, interception of precursors to the upper laser level (i.e., $\mathrm{Kr}^{*}, \mathrm{Kr}_{2}^{*}$ ) by $\mathrm{CF}_{4}$ could result in a decrease in laser performance. $\mathrm{CF}_{4}$ is also an attaching gas which forms the negative ion fragments $\mathrm{F}^{-}$and $\mathrm{CF}_{3}^{-} \cdot{ }^{6}$ Ion-ion neutralization reactions of $\mathrm{Kr}^{+}$ and $\mathrm{Kr}_{2}{ }^{+}$with $\mathrm{F}^{-}$result in excitation of the upper laser level $\mathrm{KrF}(B){ }^{7}$ Similar reactions of $\mathrm{Kr}^{+}$and $\mathrm{Kr}_{2}{ }^{+}$with
$\mathrm{CF}_{3}^{-}$may not populate $\mathrm{KrF}(B)$ and therefore may be intercepting process that reduce the density of precursors to the upper laser level. $\mathrm{CF}_{4}$ impurities can, of course, directly quench the upper laser level as well.

$\mathrm{CF}_{4}$, as well as other fluorocarbon impurities, are not absorbing at the $\operatorname{KrF}(B \rightarrow X)$ laser wavelength $(\lambda=248.4$ $\mathrm{nm}){ }^{8}$ Plasma decomposition products of the impurities, though, may be absorbing. Therefore spectroscopic analysis of the unexcited gases may not be a good indication of the absorbing potential of the impurities. Absorption at $248.9 \mathrm{~nm}$ in the laser spectrum of $\mathrm{KrF}$ has been attributed to the $\mathrm{CF}_{2}(X \rightarrow A)$ transition. ${ }^{9,10}$ The cross section for this process has been estimated to be $2 \times 10^{-17} \mathrm{~cm}^{2} .9$ Therefore significant absorption $\left(>0.05 \% \mathrm{~cm}^{-1}\right)$ occurs with $\mathrm{CF}_{2}$ concentrations of $2-3 \times 10^{13} \mathrm{~cm}^{-3}$, or $\approx 1 \mathrm{ppm}$ in atmospheric pressure mixtures.

In this paper, we report on the results of a theoretical investigation of the consequences of contamination of electron-beam-excited $\mathrm{KrF}$ lasers by $\mathrm{CF}_{4}$. This study was performed using a computer model for the plasma chemistry in e-beam-excited laser in $\mathrm{Ar} / \mathrm{Kr} / \mathrm{F}_{2}$ mixtures. We find that the impurity level of $\mathrm{CF}_{4}$ at which laser performance is significantly degraded is approximately $0.03 \%-0.01 \%$, or $300-1000 \mathrm{ppm}$, and that the degradation is a consequence of both increased quenching of precursors to the upper laser level and increased absorption.

\section{DESCRIPTION OF THE MODEL}

The model used in this study is based on a previously described simulation for an e-beam-excited $\mathrm{KrF}$ laser. ${ }^{11}$ The model accounts for the slowing of an injected $e$-beam in a high-pressure plasma, and the resulting electron kinetics, heavy particle reactions, and photophysics. The kinetics used in this work for pristine $\mathrm{Ar} / \mathrm{Kr} / \mathrm{F}_{2}$ mixtures differ little from that described in detail by Kannari, Obara, and Fujioka ${ }^{12}$ and Czuchlewski et al., ${ }^{13}$ and the reader is referred to those works for a discussion of the plasma chemistry of clean systems. Electron-impact rate coefficients and

a) Author to whom correspondence should be addressed. 
TABLE I. Fluorocarbon reactions included in the model.

\begin{tabular}{|c|c|c|}
\hline Reaction & Rate coefficient ${ }^{\mathrm{a}}$. & Reference \\
\hline$e+\mathrm{CF}_{4} \rightarrow \mathrm{CF}_{3}^{+}+\mathrm{F}+e+e$ & $7.60(-14)$ & $b, 16,25$ \\
\hline$e+\mathrm{CF}_{4} \rightarrow \mathrm{CF}_{3}+\mathrm{F}+e$ & $6.30(-14)$ & $b, 15,16$ \\
\hline$e+\mathrm{CF}_{4} \rightarrow \mathrm{CF}_{2}+\mathrm{F}+\mathrm{F}+e$ & $1.47(-13)$ & $b, 15,16$ \\
\hline$e+\mathrm{CF}_{4} \rightarrow \mathrm{CF}_{3}+\mathrm{F}^{-}$ & $1.06(-12)$ & $b, 6,16$ \\
\hline$e+\mathrm{CF}_{4} \rightarrow \mathrm{CF}_{3}^{-}+\mathrm{F}$ & $4.24(-12)$ & $b, 6,16$ \\
\hline$e+\mathrm{C}_{2} \mathrm{~F}_{6} \rightarrow \mathrm{CF}_{3}+\mathrm{CF}_{3}+e$ & $2.10(-13)$ & $b, 15,16$ \\
\hline$e+\mathrm{C}_{2} \mathrm{~F}_{4} \rightarrow \mathrm{CF}_{2}+\mathrm{CF}_{2}+e$ & $2.10(-13)$ & b, 15,16 \\
\hline$c+\mathrm{CF}_{3} \rightarrow \mathrm{CF}_{2}+\mathrm{F}+e$ & $2.10(-13)$ & $b, 15,16$ \\
\hline$e+\mathrm{CF}_{2} \rightarrow \mathrm{CF}+\mathrm{F}+e$ & $2.10(-13)$ & $b, 15,16$ \\
\hline $\mathrm{CF}_{2}+h v \rightarrow \mathrm{CF}_{2}$ & $2.00(-17) \mathrm{cm}^{2}$ & 9 \\
\hline $\mathrm{CF}_{3}^{-}+M^{+} \rightarrow \mathrm{CF}_{3}+M$ & $1.00(-06)$ & c \\
\hline $\mathrm{F}^{-}+\mathrm{C}_{n} \mathrm{~F}_{m}^{+} \rightarrow \mathrm{F}+\mathrm{C}_{n} \mathrm{~F}_{m}$ & $1.00(-06)$ & $c$ \\
\hline $\mathrm{Kr}^{+}+\mathrm{CF}_{4} \rightarrow \mathrm{CF}_{3}^{+}+\mathrm{F}+\mathrm{Kr}$ & $1.00(-11)$ & 19. \\
\hline $\mathrm{Kr}_{2}^{+}+\mathrm{CF}_{4} \rightarrow \mathrm{CF}_{3}^{+}+\mathrm{F}+\mathrm{Kr}+\mathrm{Kr}$ & $1.00(-11)$ & $\mathrm{d}, 19$ \\
\hline $\mathrm{Ar}^{+}+\mathrm{CF}_{4} \rightarrow \mathrm{CF}_{3}^{+}+\mathrm{F}+\mathrm{Ar}$ & $9.58(-10)$ & $\mathrm{e}, 20$ \\
\hline $\mathrm{Ar}_{2}^{+}+\mathrm{CF}_{4} \rightarrow \mathrm{CF}_{3}^{+}+\mathrm{F}+\mathrm{Ar}+\mathrm{Ar}$ & $9.58(-10)$ & $\mathrm{d}, 20$ \\
\hline $\mathrm{CF}^{+}+\mathrm{CF}_{4} \rightarrow \mathrm{CF}_{3}^{+}+\mathrm{CF}_{2}$ & $3.30(-10)$ & 19 \\
\hline $\mathrm{CF}^{+}+\mathrm{C}_{2} \mathrm{~F}_{6} \rightarrow \mathrm{C}_{2} \mathrm{~F}_{5}^{+}+\mathrm{CF}_{2}$ & $3.90(-11)$ & 19 \\
\hline $\mathrm{CF}^{+}+\mathrm{C}_{3} \mathrm{~F}_{8} \rightarrow \mathrm{C}_{3} \mathrm{~F}_{7}^{+}+\mathrm{CF}_{2}$ & $7.10(-11)$ & 19 \\
\hline $\mathrm{CF}_{3}+\mathrm{F} \rightarrow \mathrm{CF}_{4}$ & $2.90(-11)$ & $f, 15,26$ \\
\hline $\mathrm{CF}_{2}+\mathrm{F} \rightarrow \mathrm{CF}_{3}$ & $1.30(-11)$ & $\mathrm{f}, 15$ \\
\hline $\mathrm{CF}+\mathrm{F} \rightarrow \mathrm{CF}_{2}$ & $1.00(-11)$ & $f, 15$ \\
\hline $\mathrm{C}_{2} \mathrm{~F}_{4}+\mathrm{F} \rightarrow \mathrm{CF}_{3}+\mathrm{CF}_{2}$ & $4.00(-11)$ & $15^{\circ}$ \\
\hline $\mathrm{C}_{2} \mathrm{~F}_{5}+\mathrm{F} \rightarrow \mathrm{CF}_{3}+\mathrm{CF}_{3}$ & $1.00(-11)$ & 15 \\
\hline $\mathrm{CF}+\mathrm{CF}_{2} \rightarrow \mathrm{C}_{2} \mathrm{~F}_{3}$ & $1.00(-12)$ & $f, 15$ \\
\hline $\mathrm{C}_{2} \mathrm{~F}_{3}+\mathrm{F} \rightarrow \mathrm{C}_{2} \mathrm{~F}_{4}$ & $1,00(-12)$ & $\mathrm{f}, 15$ \\
\hline $\mathrm{CF}_{2}+\mathrm{CF}_{3} \rightarrow \mathrm{C}_{2} \mathrm{~F}_{5}$ & $1.00(-12)$ & $f, 15$ \\
\hline $\mathrm{CF}_{3}+\mathrm{F}_{2} \rightarrow \mathrm{CF}_{4}+\mathrm{F}$ & $1.04(-12)$ & 25 \\
\hline $\mathrm{CF}_{2}+\mathrm{CF}_{2} \rightarrow \mathrm{C}_{2} \mathrm{~F}_{4}$ & $5.00(-14)$ & $\mathrm{f}, 15,28$ \\
\hline $\mathrm{CF}_{3}+\mathrm{CF}_{3} \rightarrow \mathrm{C}_{2} \mathrm{~F}_{6}$ & $8.30(-12)$ & 3,15 \\
\hline $\mathrm{CF}_{3}^{-}+\mathrm{F} \rightarrow \mathrm{CF}_{3}+\mathrm{F}^{-}$ & $5.00(-08)$ & 29 \\
\hline $\mathrm{Ar}^{*}+\mathrm{CF}_{4} \rightarrow \mathrm{CF}_{2}+\mathrm{F}_{2}+\mathrm{Ar}$ & $4.00(-11)$ & $\mathrm{g}, 5$ \\
\hline $\mathrm{Ar}^{* *}+\mathrm{CF}_{4} \rightarrow \mathrm{CF}_{2}+\mathrm{F}_{2}+\mathrm{Ar}$ & $4.00(-11)$ & $\mathrm{d}, 5$ \\
\hline $\mathrm{Ar}^{*}+\mathrm{C}_{2} \mathrm{~F}_{6} \rightarrow \mathrm{CF}_{3}+\mathrm{CF}_{3}+\mathrm{Ar}$ & $4.00(-11)$ & $d, 5$ \\
\hline $\mathrm{Ar}^{* *}+\mathrm{C}_{2} \mathrm{~F}_{6} \rightarrow \mathrm{CF}_{3}+\mathrm{CF}_{3}+\mathrm{Ar}$ & $4.00(-11)$ & d,5 \\
\hline $\mathrm{Ar}_{2}^{*}+\mathrm{CF}_{4} \rightarrow \mathrm{CF}_{2}+\mathrm{F}_{2}+\mathrm{Ar}+\mathrm{Ar}$ & $4.00(-11)$ & $\mathrm{d}, 5$ \\
\hline $\mathrm{Ar}_{2}^{*}+\mathrm{C}_{2} \mathrm{~F}_{6} \rightarrow \mathrm{CF}_{3}+\mathrm{CF}_{3}+\mathrm{Ar}+\mathrm{Ar}$ & $4.00(-11)$ & d,5 \\
\hline $\mathrm{Kr}^{*}+\mathrm{CF}_{4} \rightarrow \mathrm{CF}_{4}+\mathrm{Kr}$ & $7.00(-13)$ & 5 \\
\hline $\mathrm{Kr}^{* *}+\mathrm{CF}_{4} \rightarrow \mathrm{CF}_{4}+\mathrm{Kr}$ & $7.00(-13)$ & $\mathrm{d}, 5$ \\
\hline $\mathrm{Kr}^{*}+\mathrm{C}_{2} \mathrm{~F}_{6} \rightarrow \mathrm{C}_{2} \mathrm{~F}_{6}+\mathrm{Kr}$ & $7.00(-13)$ & $\mathrm{d}, 5$ \\
\hline $\mathrm{Kr}^{* *}+\mathrm{C}_{2} \mathrm{~F}_{6} \rightarrow \mathrm{C}_{2} \mathrm{~F}_{6}+\mathrm{Kr}$ & $7.00(-13)$ & $\mathrm{d}, 5$ \\
\hline $\mathrm{Kr}_{2}^{*}+\mathrm{CF}_{4} \rightarrow \mathrm{CF}_{4}+\mathrm{Kr}+\mathrm{Kr}$ & $7.00(-13)$ & $\mathrm{d}, 5$ \\
\hline $\mathrm{Kr}_{2}^{*}+\mathrm{C}_{2} \mathrm{~F}_{6} \rightarrow \mathrm{C}_{2} \mathrm{~F}_{\mathrm{h}}+\mathrm{Kr}+\mathrm{Kr}$ & $7.00(-13)$ & d,5. \\
\hline $\mathrm{KrF}(B)+\mathrm{C}_{n} \mathrm{~F}_{m} \rightarrow \mathrm{Kr}+\mathrm{F}+\mathrm{C}_{n} \mathrm{~F}_{m}$ & $1.00(-11)$ & $\mathrm{h}$ \\
\hline $\mathrm{ArF}(B)+\mathrm{C}_{n} \mathrm{~F}_{m} \rightarrow \mathrm{Ar}+\mathrm{F}+\mathrm{C}_{n} \mathrm{~F}_{m}$ & $2.00(-11)$ & $\mathrm{h}$ \\
\hline
\end{tabular}

Units of $\mathrm{cm}^{3} \mathrm{~s}^{-1}$ unless noted.

${ }^{b}$ Rate coefficient was obtained from the Monte Carlo simulation for slowing of an $e$-beam in an $\mathrm{Ar} / \mathrm{Kr} / \mathrm{F}_{2} / \mathrm{CF}_{4}$ mixture using the $\mathrm{CF}_{4}$-cross sections in Ref. 16, and branching ratios in the cited reference.

"Estimated. See Ref. 12 for analogous reactions.

dEstimated. See text and cited reference.

"Value is the maximum in the range of uncertainty.

Rate constant for a three-body association reaction is quoted using its equivalent two-body rate coefficient at $1.75 \mathrm{~atm}$. See Ref. 15 .

${ }^{2}$ See text for discussion of branching.

${ }^{\mathrm{h}}$ Estimated. See text for discussion.

$W$ values used in our model were obtained from a separate Monte Carlo simulation for the slowing of $e$ beams in highpressure gases. ${ }^{14}$

In addition to the conventional plasma chemistry of $e$-beam-pumped $\mathrm{KrF}$ lasers, we included reactions pertaining to the plasma decomposition of $\mathrm{CF}_{4}$. These reactions are listed in Table I. The choice of reaction pathways was largely based on the work of Plumb and Ryan who have investigated the plasma kinetics of $\mathrm{CF}_{4}$ in the context of the etching of silicon. ${ }^{15}$ Rate coefficients for electron-impact processes for $\mathrm{CF}_{4}$ were also obtained from the Monte Carlo simulation by including the cross sections derived by Hayashi. ${ }^{16}$

The threshold for electron-impact dissociation of $\mathrm{CF}_{4}$ is $\simeq 12.5 \mathrm{eV} .{ }^{17}$ Therefore quenching reactions of $\mathrm{CF}_{4}$ with Ar (4s) and Art are capable of dissociating the fluorocarbon whereas those with $\mathrm{Kr}(5 s)$ and $\mathrm{Kr}_{2}^{*}$ are not likely to dissociate the molecule. As a worst case, we therefore assumed that quenching reactions of $\mathrm{CF}_{4}^{*}$ with $\mathrm{Ar}^{*}$ and $\mathrm{Ar}_{2}^{*}$ are dissociative resulting in $\mathrm{CF}_{2}+2 \mathrm{~F}$. We included no branching to $\operatorname{KrF}(B)$ or $\operatorname{ArF}(B)$ for quenching reactions of $\mathrm{Kr}^{*}, \mathrm{Kr}_{2}^{*}, \mathrm{Ar}^{*}$, or Ar. with $\mathrm{C}_{n} \mathrm{~F}_{m}$ species, in analogy with measurements for quenching of $\mathrm{Kr}(5 \mathrm{~s})$ by $\mathrm{CF}_{4}$ made by Velazco and co-workers. ${ }^{5}$ Branchings to $\operatorname{KrF}(B)$ and $\operatorname{ArF}(B)$ have been measured for ion neutralization between $\mathrm{Kr}^{+}$and $\mathrm{Ar}^{+}$with $\mathrm{SF}_{6}^{-}$, showing that this type of process can result in excitation of the upper laser level when complex ions are reactants. ${ }^{18}$ As a worst case, though, we assumed that neutralization of $\mathrm{Kr}^{+}$and $\mathrm{Kr}_{2}^{+}$with $\mathrm{CF}_{3}^{-}$is nondissociative with no branching to $\operatorname{KrF}(B)$.

The thermochemistry of $\mathrm{CF}_{4}$ and $\mathrm{CF}_{3}{ }^{+}$implies that charge exchange reactions with $\mathrm{Ar}^{+}$are exothermic by 1.1 $\mathrm{eV}$ whereas those with $\mathrm{Kr}^{+}$are endothermic by $0.76 \mathrm{eV} .^{20}$ Charge exchange reactions of $\mathrm{Ar}^{+}$with $\mathrm{CF}_{4}$ producing $\mathrm{CF}_{3}{ }^{+}$have been measured at thermal energies yielding a gas kinetic rate coefficient $\left[7( \pm 2.6) \times 10^{-10} \mathrm{~cm}^{3} \mathrm{~s}^{-1}\right]^{20}$ A smaller rate coefficient has been measured for charge exchange with $\mathrm{Kr}^{+}\left(1 \times 10^{-11} \mathrm{~cm}^{3} \mathrm{~s}^{-1}\right){ }^{19}$. In analogy to these results, we assumed that all charge-exchange reactions between $\mathrm{Kr}^{+}, \mathrm{Kr}_{2}^{+}, \mathrm{Ar}^{+}$, and $\mathrm{Ar}_{2}^{+}$have a unity branching to $\mathrm{CF}_{3}^{+}$with rates given by the monomer species.

Rate coefficients for the quenching of $\operatorname{KrF}(B)$ and $\operatorname{ArF}(B)$ by $C_{4}$ are not presently available. The coefficients for quenching of $\mathrm{XeF}(B)$ and $\mathrm{XeCl}(B)$ by $\mathrm{CF}_{4}$ are $0.5 \times 10^{-12}$ (Ref. 21 ) and $2.5 \times 10^{-12} \mathrm{~cm}^{3} \mathrm{~s}^{-1,22}$ respectively. These values are small due to the absence of acceptor states in $\mathrm{CF}_{4}$ at the energies of $\mathrm{XeF}(B)(3.5 \mathrm{eV})$ and $\mathrm{XeCl}(B)(4.0 \mathrm{eV})$. One normally expects, though, that the rate coefficients for quenching under these conditions will increase with increasing energy of the rare-gas halide, as shown by the increase in the rate coefficient of $\mathrm{XeCl}(B)$ compared to $\mathrm{XeF}(B)$. We therefore estimated as a worst case that the rate coefficients for quenching of $\mathrm{KrF}(B)$ (energy of $5 \mathrm{eV}$ ) and $\operatorname{ArF}(B)$ (energy at $6.5 \mathrm{eV}$ ) by $\mathrm{CF}_{4}$ are $1.0 \times 10^{-11}$ and $2.0 \times 10^{-11} \mathrm{~cm}^{3} \mathrm{~s}^{-1}$, respectively: As discussed below, even with these values quenching of the excimer species by $\mathrm{CF}_{4}$ has a small effect on the performance of the laser.

\section{RESULTS FOR CONTAMINATION OF KrF LASERS BY $\mathrm{CF}_{4}$}

The pumping conditions we chose were $\mathrm{A} r \mathrm{r} / \mathrm{Kr} /$ $\mathrm{F}_{2}=95 / 5 / 0.5$ at $1.75 \mathrm{~atm}$ with a power deposition of 100 $400 \mathrm{~kW} \mathrm{~cm}^{-3}$ having a current pulse of $400 \mathrm{~ns}$ (FWHM). 


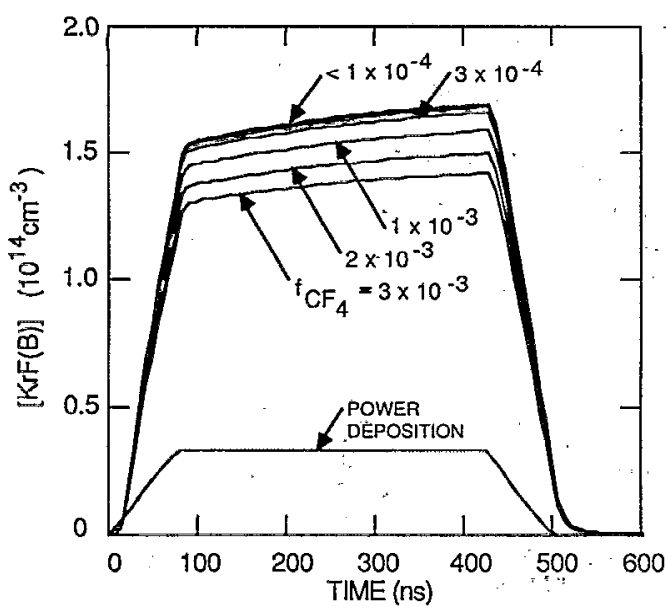

(a)

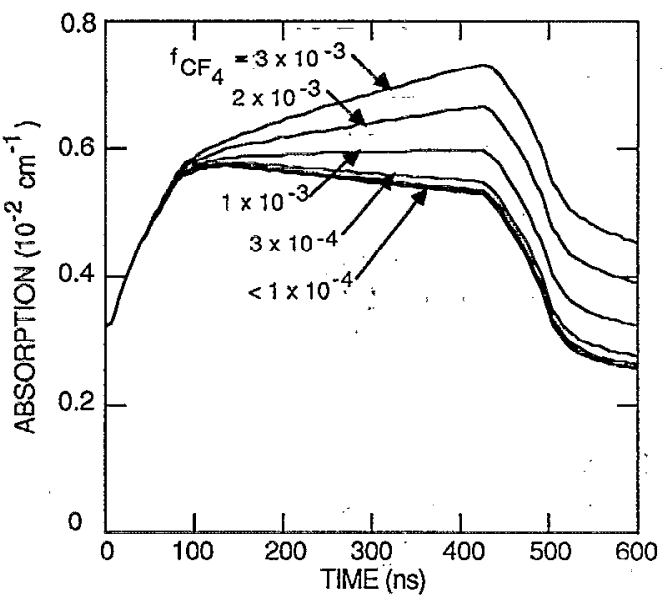

(b)

FIG. 1. Laser parameters for $e$-beam excitation of a 1.75-atm Ar/ $/ \mathrm{Kr} /$ $F_{2}=95 / 5 / 0.5$ gas mixture for different levels of $\mathrm{CF}_{4}$ impurity: (a) $\mathrm{KrF}(B)$ density and (b) total absorption. The power deposition is 250 $\mathrm{kW} \mathrm{cm}{ }^{-3} \cdot f_{\mathrm{CF}_{4}}$ is the mole fraction of $\mathrm{CF}_{4}$ in the mixture. Absorption increases during the current pulse due to buildup of $\mathrm{CF}_{2}$.

These values are similar to those used in the larger aperture module (LAM) laser system at Los Alamos National Laboratory whose performance history motivated this work. ${ }^{23}$ The computed density of $\operatorname{KrF}(B)$ and absorption $\alpha$ as a function of time are shown in Fig. 1 for a power deposition of $250 \mathrm{~kW} \mathrm{~cm}-3$ and various levels of $\mathrm{CF}_{4}$ contamination. The density of $\operatorname{KrF}(B)$ we obtained in a pristine mixture corresponds to a small signal gain of $\simeq 0.04 \mathrm{~cm}^{-1}$ for a stimulated emission cross section of $2.6 \times 10^{-16} \mathrm{~cm}^{2} .{ }^{12}$ This gain, and absorption of $0.055 \mathrm{~cm}^{-1}$, agree well with recent and past measurements of these quantities in $e$-beam-excited $\mathrm{KrF}$ lasers. These experimental results are summarized in Ref. 24.

For a power deposition of $250 \mathrm{~kW} \mathrm{~cm}{ }^{-3}$ and pulse : length of $400 \mathrm{~ns}(\simeq 100 \mathrm{~J} / \mathrm{l})$ the $\mathrm{CF}_{4}$ is not significantly depleted. The $\mathrm{KrF}(B)$ density increases moderately during the current pulse as $\mathrm{F}_{2}$, a dominant quencher, is depleted by dissociative attachment reactions. With $\mathrm{CF}_{4}$ contamination, the density of $\operatorname{KrF}(B)$ is uniformly decreased during the current pulse, with a significant decrease occurring when the mole fraction of $\mathrm{CF}_{4}, f\left(\mathrm{CF}_{4}\right)$, exceeds $3 \times 10^{-4}$,

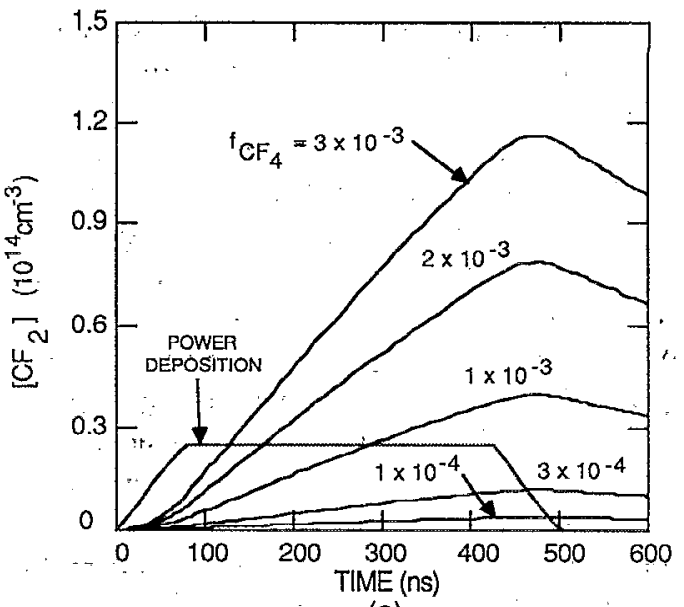

(a)

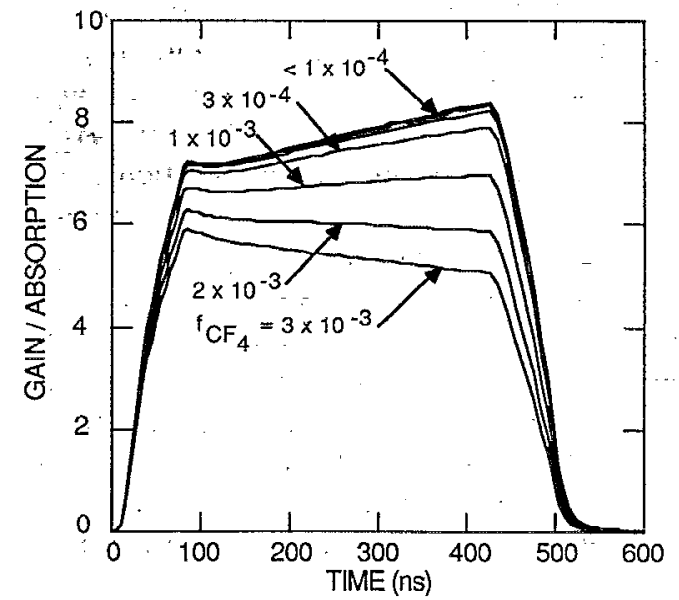

...(b)

FIG. 2. Laser parameters for the conditions of Fig. 1: (a) $\mathrm{CF}_{2}$ density and (b) $g_{0} / \alpha$ (small signal gain/absorption). The increase in $\mathrm{CF}_{2}$ during the pulse causes a decrease in $g_{0} / \alpha$. This quantity usually increases due to burnup of $F_{2}$.

or $300 \mathrm{ppm}$. This trend indicates that $\mathrm{CF}_{4}$ is the dominant quenching or intercepting species which reduces $\operatorname{KrF}(B)$ as opposed to its dissociation products. $F_{2}$ accounts for approximately $60 \%$ of the total absorption at $248 \mathrm{~nm}$ in the absence of contamination. The absorption normally decreases during the current pulse due to burnup of $\mathrm{F}_{2}$ (approximately $25 \%$ in these cases). In the presence of contamination, absorption increases both as the $\mathrm{CF}_{4}$ concentration increases and as the current pulse progresses. These results imply that products of $\mathrm{CF}_{4}$ that are relatively" unreactive and accumulate during the current pulse contribute to the incremental increase in absorption. The contamination threshold for $\mathrm{CF}_{4}$ to produce sig: nificant additional absorption is greater than hundreds of ppm.

The species responsible for the increase in absorption in our reaction scheme is $\mathrm{CF}_{2}$, whose density is shown in Fig. 2(a) for the same conditions as in Fig. 1. Densities in excess of $10^{13} \mathrm{~cm}^{-3}$ are generated in heavily contaminated systems $\left[f\left(\mathrm{CF}_{4}\right)>10^{-4}\right]$. Although $\mathrm{CF}_{3}^{-}$is absorbing at $248 \mathrm{~nm}$, the rate constant for dissociative attachment to $\mathrm{CF}_{4}$ is small $\left(\approx 5 \times 10^{-12} \mathrm{~cm}^{3} \mathrm{~s}^{-1}\right)$ due to the high 
threshold energy for the process $(\approx 5 \mathrm{eV}){ }^{6} \mathrm{CF}_{3}^{-}$also charge exchanges with $\mathrm{F}$. The density of $\mathrm{CF}_{3}^{-}$, therefore, does not exceed $10^{10} \mathrm{~cm}^{-3}$ for most conditions and consequently does not contribute significantly to absorption.

$\mathrm{CF}_{2}$ is relatively unreactive in this mixture since it does not react exothermically with $\mathrm{CF}_{4}$. Therefore, the density of $\mathrm{CF}_{2}$ tends to integrate during the current pulse. As a result of $\mathrm{CF}_{2}$ accumulating during the current pulse the absorption also increases, resulting in a decrease in $g_{0} / \alpha$ (small signal gain/absorption), as shown in Fig. 2(b). Since $g_{0} / \alpha$ is a measure of the extraction efficiency, the laser efficiency also decreases during the current pulse (see below). The dominant sink for $\mathrm{CF}_{2}$ is association reactions with atomic fluorine to form $\mathrm{CF}_{3}\left(\mathrm{CF}_{2}+\mathrm{F} \rightarrow \mathrm{CF}_{3}\right)$, having approximately a $300 \mathrm{~ns}$ time constant. This reaction can be followed by a second reassociation reaction to reform $\mathrm{CF}_{4}$ $\left(\mathrm{CF}_{3}+\mathrm{F} \rightarrow \mathrm{CF}_{4}\right) \cdot \mathrm{CF}_{2}$ therefore recycles to some degree during the pulse, being reformed by electron impact and dissociative excitation transfer to $\mathrm{CF}_{3}$ and $\mathrm{CF}_{4}$ from $\mathrm{Ar}^{*}$. Although $\mathrm{CF}_{2}$ and $\mathrm{CF}_{3}$ undergo mutual association reactions to form $\mathrm{C}_{2} \mathrm{~F}_{4}, \mathrm{C}_{2} \mathrm{~F}_{5}$, and $\mathrm{C}_{2} \mathrm{~F}_{6}$, the rate constants for these processes are not particularly large $\left(<10^{-12}\right.$ $\left.\mathrm{cm}^{3} \mathrm{~s}^{-1}\right)$. Since the density of $F\left(10^{16}-10^{17} \mathrm{~cm}^{-3}\right)$ greatly exceeds that of $\mathrm{CF}_{2}$ and $\mathrm{CF}_{3}\left(<10^{14} \mathrm{~cm}^{-3}\right)$ association reactions with $\mathrm{F}$ are most important in determining the density of $\mathrm{CF}_{2}, \mathrm{C}_{2} \mathrm{~F}_{5}$ and $\mathrm{C}_{2} \mathrm{~F}_{4}$ also back react with $F$ atoms with moderatc rate coefficients $\left(>10^{-11} \mathrm{~cm}^{3} \mathrm{~s}^{-1}\right.$ ) to form $\mathrm{CF}_{2}$ and $\mathrm{CF}_{3}$. The end result is that $\mathrm{C}_{2} \mathrm{~F}_{6}$ is the only fluorocarbon dimer having a density that exceeds $10^{13} \mathrm{~cm}^{-3}$ when $f\left(\mathrm{CF}_{4}\right)$ is larger than $10^{-3} \cdot \mathrm{C}_{2} \mathrm{~F}_{6}$ is not chemically reactive (other than being dissociated by electron impact or excitation transfer) and is not absorbing at $248 \mathrm{~nm}^{8}$ Therefore, it is not additionally harmful.

Laser power as a function of time and laser power efficiency at $425 \mathrm{~ns}$ as a function of $f\left(\mathrm{CF}_{4}\right)$ are shown in Fig. 3 for the same conditions discussed above. As the level of $\mathrm{CF}_{4}$ contamination increases, the laser power switches from increasing during the current pulse to decreasing during the current pulse. This trend is a consequence of the accumulation of $\mathrm{CF}_{2}$ which reduces $g_{0} / \alpha$ during the current pulse. This compensates the burnup of $F_{2}$ which otherwise results in $g_{0} / \alpha$ increasing during the current pulse. Laser power efficiency $\eta$ consequently decreases from $6.4 \%$ in a pristine mixture to $3.8 \%$ for. $f\left(\mathrm{CF}_{4}\right)=3 \times 10^{-3}$. This yields an incremental slope effciency of $\beta=(\Delta \eta / \eta) / \Delta f\left(\mathrm{CF}_{4}\right)$ of $-2 \times 10^{-4} / \mathrm{ppm}$. Kimura and Seamans obtained a similar sensitivity of $\beta=-3 \times 10^{-4}$ in their measurements of laser efficiency in an e-beam-pumped $\mathrm{XeF}$ laser during controlled addition of impurities. ${ }^{4}$

To identify the kinetics dominantly contributing to the reduction in $\operatorname{KrF}(B)$ density, we defined two processes: direct interception and indirect interception. Indirect interception processes are those in which $\mathrm{CF}_{4}$ quenches a highorder precursor to forming $\mathrm{KrF}(B)$. For example,

$$
\operatorname{ArF}(B)+\mathrm{CF}_{4} \rightarrow \mathrm{Ar}+\mathrm{F}+\mathrm{CF}_{4}
$$

is an indirect interception reaction of the process

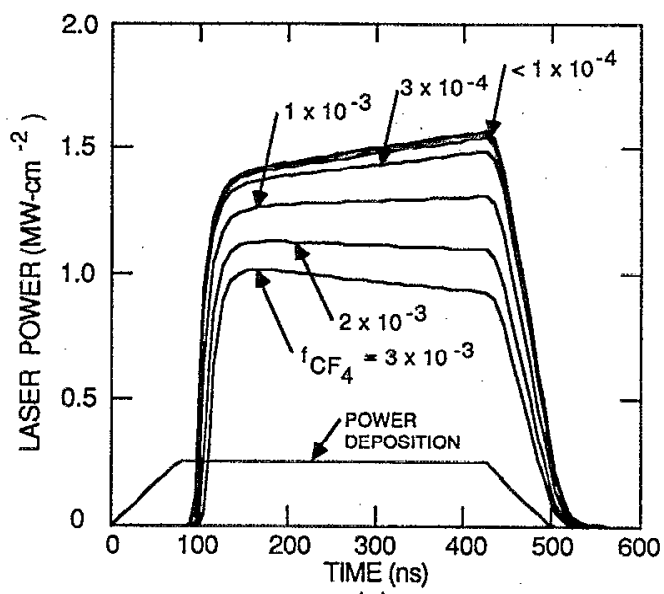

(a)

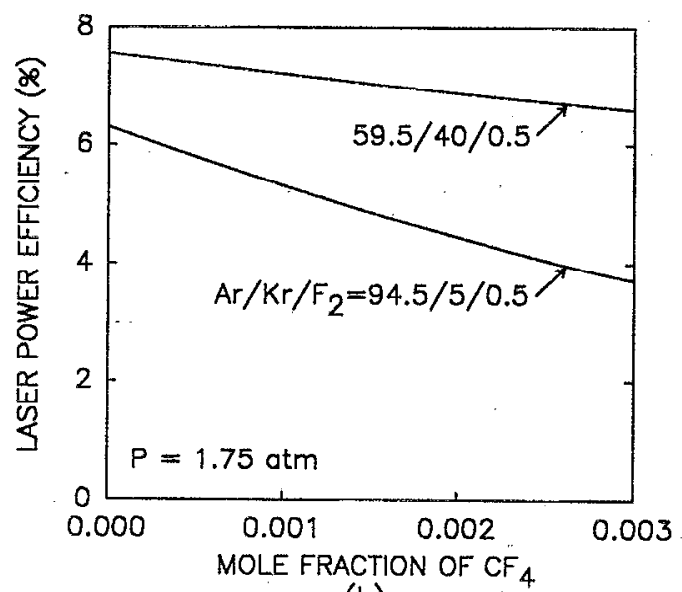

(b)

FIG. 3. Laser performance for different levels of $\mathrm{CF}_{4}$ contamination: (a) laser power and (b) laser power efficiency at $425 \mathrm{~ns}$. The conditions are nominally the same as for Fig. 1. Laser power efficiency is shown for two gas mixtures, showing that mixtures having higher proportions of $\mathrm{Kr}$ are less sensitive to $\mathrm{CF}_{4}$ contamination.

$$
\operatorname{ArF}(B)+\mathrm{Kr} \rightarrow \mathrm{KrF}(B)+\mathrm{Ar} .
$$

A direct interception reaction quenches a first-order reactant leading to $\operatorname{KrF}(B)$. For example the quenching process

$$
\mathrm{Kr}(5 s)+\mathrm{CF}_{4} \rightarrow \mathrm{Kr}+\mathrm{CF}_{4}
$$

would intercept directly the reaction

$$
\mathrm{Kr}(5 s)+\mathrm{F}_{2} \rightarrow \mathrm{KrF}(B)+\mathrm{F} .
$$

Indirect interception most often involves quenching of Arexcited species whereas direct interception involves quenching of $\mathrm{Kr}$ excited species. Direct quenching reactions are collisions of $\mathrm{CF}_{4}$ and its reaction products with $\operatorname{KrF}(B)$.

The density of $\operatorname{KrF}(B)$ is plotted in Fig. 4 as a function of time during the current pulse with and without $\mathrm{CF}_{4}$ as an impurity $\left[f\left(\mathrm{CF}_{4}\right)=2.0 \times 10^{-3}\right]$. Results are also shown for excluding indirect interception reactions, direct interception reactions, and direct quenching reactions, respectively. Direct quenching of $\mathrm{KrF}(B)$ by $\mathrm{CF}_{4}$ contrib- 


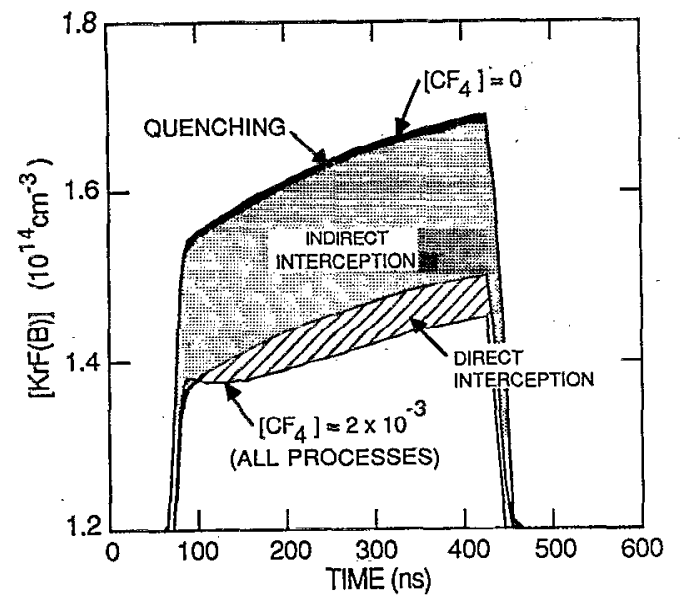

FIO. 4. $\operatorname{KrF}(B)$ density during the current pulse with and without contamination by $\mathrm{CF}_{4}$ (mole fraction of $2 \times 10^{-3}$ ). Results are shown for excluding direct interception, indirect interception, and quenching reactions. The cross-hatched and dotted regions shown the contributions of quenching and indirect interception to the decrease in the $\operatorname{KrF}(B)$ density.

utes only a few percent to the decrease in the density of the upper laser level. Direct interception of $\mathrm{Kr}^{*}$, $\mathrm{Kr}^{+}, \mathrm{Kr}_{2}^{+}$, and $\mathrm{F}^{-}$causes a larger, but moderate decrease. The majority of the decrease in the density of $\mathrm{KrF}(B)$ results from indirect interception reactions. This trend results from the rates of quenching of $\mathrm{Ar}^{*}$ being larger than those for $\mathrm{Kr}^{*}$, and because the density of $\mathrm{Ar}$ precursors are more numerous. Gas mixtures having large fractions of $\mathrm{Kr}$ should therefore be less sensitive to contamination by $\mathrm{CF}_{4}$. This result is shown in Fig. 3(b) where laser power efficiency is plotted as a function of $f\left(\mathrm{CF}_{4}\right)$ for an $\mathrm{Ar} / \mathrm{Kr} / \mathrm{F}_{2}=59.5 / 40 / 0.5$ mixture. The decrease in laser efficiency is less than a third that in the leaner mixture.

A large portion of the deleterious effects of contamination by $\mathrm{CF}_{4}$ results from accumulation of $\mathrm{CF}_{2}$. For a given pumping rate absorption increases as the pulse length, and energy deposition, increase. When the power deposition is increased the rate of generation of $\mathrm{CF}_{2}$ increases but so does the gain. There is, then, a compensating effect on $g_{0} / \alpha$. The relative amount that $g_{0} / \alpha$ decreases should not change significantly as power deposition is varied. The scaling parameter of interest should then be energy deposition because for short pulses $(<1 \mu \mathrm{s})$ the density of $\mathrm{CF}_{2}$ is ultimately determined by energy deposition and not power deposition. This scaling is shown in Fig. 5 where $g_{0} / \alpha$ and $\left[\mathrm{CF}_{2}\right]$ are each plotted as a function of power deposition for a fixed energy deposition of $100 \mathrm{~J} / 1$. Values are shown for a pristine mixture and with $f\left(\mathrm{CF}_{4}\right)=1.5 \times 10^{-3}$. The density of $\mathrm{CF}_{2}$ does not change significantly at a fixed energy deposition for power depositions of $100-400 \mathrm{~kW} \mathrm{~cm}{ }^{-3} \cdot g_{0} / \alpha$ increases with increasing power deposition, but the ratio between the pristine and contaminated mixtures remains nearly the same.

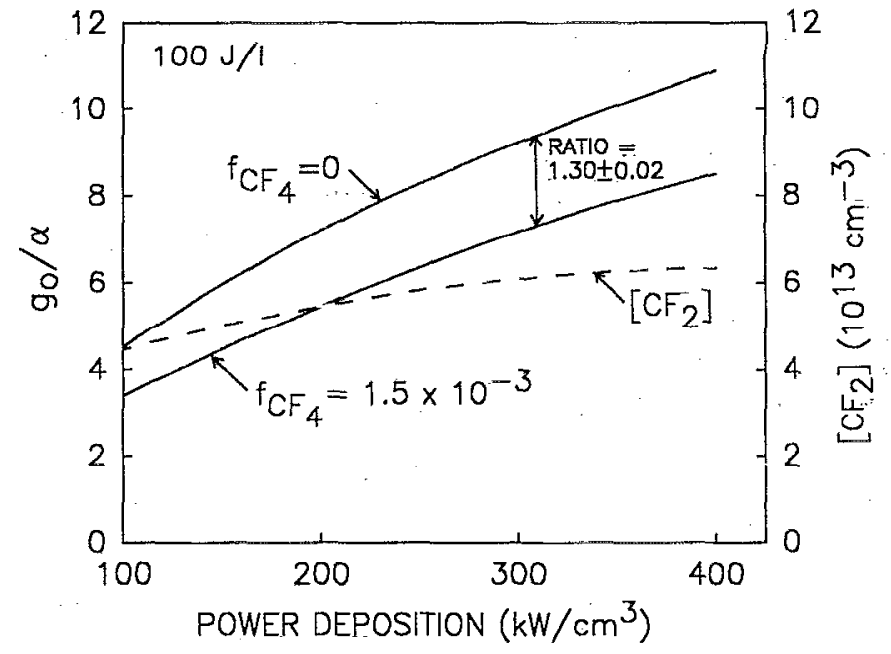

FIG. 5. $g_{0} / \alpha$ (small signal gain/absorption) and $\mathrm{CF}_{2}$ density for various power depositions having a total energy deposition of $100 \mathrm{~J} / 1$. Results are shown with and without $\mathrm{CF}_{4}$ contamination The ratio between these values is nearly constant, showing that energy deposition is the scaling parameter of interest for contamination by $\mathrm{CF}_{4}$.

\section{CONCLUDING REMARKS}

The performance of $e$-beam-cxcited $\mathrm{KrF}$ lasers contaminated by $\mathrm{CF}_{4}$ has been theoretically investigated. We find that impurity levels in excess of hundreds of ppm are required to significantly degrade laser efficiency. $\mathrm{KrF}$ lasers are similar to $\mathrm{XeF}$ lasers in this respect. ${ }^{4}$ The density of $\mathrm{KrF}(B)$ decreases with increasing $\mathrm{CF}_{4}$ density primarily due to quenching of excited states of argon, which are indirect precursors to formation of the upper laser level. Absorption increases due primarily to the accumulation of $\mathrm{CF}_{2}$ during the current pulse. The cited impurity levels are large compared to the values believed to be present in $e$-beam-pumped laser systems showing symptoms of fluorocarbon contamination, ${ }^{30}$ though they are commensurate with that which might be found in some discharge-excited systems. This leads one to suspect that other trace fluorocarbon impurities have either a greater quenching or intercepting capability, or generate $\mathrm{CF}_{2}$ by plasma decomposition at a higher rate than $\mathrm{CF}_{4}$.

Due to the high threshold energy for dissociation of $\mathrm{CF}_{4}(12.5 \mathrm{eV})$ and the low electron temperature in e-beam-pumped lasers $\left(T_{E} \simeq 1 \mathrm{eV}\right)$, the rate of electron impact dissociation of $\mathrm{CF}_{4}$ by bulk electrons is low. Electric discharge lasers, however, have electron temperatures of 4-5 eV. The rate of dissociation of $\mathrm{CF}_{4}$, as well as other fluorocarbon impurities, will be many times larger in discharge-excited lasers than that in e-beam-pumped systems. One can, therefore, expect electric discharge $\mathrm{KrF}$ lasers to be more sensitive to $\mathrm{CF}_{4}$ than $e$-beam-pumped lasers having the same degree of contamination.

\section{ACKNOWLEDGMENTS}

The authors would like to thank D. Hanson and C. Patterson of Los Alamos National Laboratory for their comments during the course of this investigation. The aur 
thors also would like to thank Professor D. W. Setser for discussions on quenching mechanisms. This work was supported by Los Alamos National Laboratory and the National Science Foundation under the Research Experience for Undergraduates Program (CTS 88-03170 REU).

${ }^{1}$ M. C. Gower, A. J. Kearsley, and C. E. Webb, J. Quantum Electron. 16, 231 (1980).

${ }^{2}$ A. E. Mandl and H. Hyman, Appl. Phys. Lett. 49, 841 (1986).

${ }^{3}$ J. Brannon, J. Quantum Electron. 18, 1302 (1982).

${ }^{4}$ W. D. Kimura and J. F. Seamans, J. Quantum Electron. 24, 2121 (1988).

5J. E. Velazco, J. H. Koltz, and D. W. Setser, J. Chem. Phys. 65, 3468 (1976).

${ }^{6}$ S. M. Spyrou, I. Sauers, and L. G. Christophorou, J. Chem. Phys. 78, 7200 (1983).

${ }^{7}$ W. L. Morgan, B. L. Whitten, and J. N. Bardsley, Phys. Rev. Lett. 45, 2021 (1980).

${ }^{8}$ P. J. Hargis (unpublished data).

${ }^{9} \mathrm{C}$. W. Patterson and D. E. Hanson, International Conference on Lasers 89, New Orleans, December 1989, paper HB.2.

${ }^{10}$ D. S. King, P. K. Schenk, and J. C. Stephanson, J. Mol. Spectrosc. 78, 1 (1979).

${ }^{11}$ M. J. Kushner, J. Quantum Electron. 26, 1546 (1990).

${ }^{12}$ F. Kannari; M. Obara, and T. Fujioka, J. Appl. Phys. 57, 4309 (1985).

${ }^{13}$ S. J. Czuchlewski, D. E. Hanson, R. J. Krohn, A. R. Larson, and E. T. Salesky, Fusion Technol. 11, 560 (1987).

${ }_{14}$ M. J. Kushner, J. Appl. Phys. 66, 2297 (1989).

${ }^{15}$ K. R. Ryan and J. C. Plumb, Plasma Chem. Plasma Proc. 6, 231 (1986).
${ }^{16} \mathrm{M}$. Hayashi, in Swarm Studies and Inelastic Electron-Molecule Collisions, edited by L. C. Pitchford, B. V. McKoy, A. Chutjian, and S. Trajmar (Springer, New York, 1987), p. 167.

${ }^{17}$ H. F. Winters and M. Inokuti, Phys. Rev. A. 25, 1420 (1982).

${ }^{18}$ M. Tsuji, M. Furusawa, and Y. Nishimura, Chem. Phys. Lett. 166, 363 (1990).

${ }^{19}$ Y. Ikezoe, S. Matsuoka, M. Takebe, and A. Viggiano, "Gas Phase Ion-Molecule Reaction Rate Constants Through 1986," Ion Reaction Research Group of the Mass Spectroscopy Society of Japan, 1987.

${ }^{20}$ E. Fisher, M. E. Weber, and P. B. Armentrout, J. Chem. Phys. 92, 2296 (1990).

${ }^{21}$ H. C. Brashears and D. W. Setser, J. Chem. Phys. 76, 4932 (1982).

${ }^{22} \mathrm{D}$. W. Setser (private communication).

${ }^{23}$ L. Rosocha, J. Hanlon, J. McLeod, M. Kang, B. Kortegaard, M. Burrows, and P. Bowling, Fusion Technol. 11, 497 (1987).

${ }^{24}$ D. C. Thompson, R. Fedosejevs, A. A. Offenberger, J. D. Santigo, and H. R. Manjunath, J. Quantum Electron. 25, 2161 (1989).

${ }^{25}$ K. Stephan, H. Deustch, and T. D. Mark, J. Chem. Phys. 83, 5712 (1985).

${ }^{26}$ N. Selamoglu, M. J. Rossi, and D. M. Golden, Chem. Phys. Lett. 124, 69 (1990).

${ }^{27}$ S. Seeger, G. Rotzoll, A. Lubbert, and K. Schugerl, Int. J. Chem. Kinet. 14, 457 (1982).

${ }^{28}$ S. Sharpe, B. Hartnet, H. S. Sethi, and D. S. Sethi, J. Photochem. 38, 1 (1987).

${ }^{29}$ G. K. Vinogradov, P. I. Nevzorov, L. S. Polak, and K. I. Slovetsky, Vacuum 32, 592 (1982).

${ }^{30}$ D. E. Hanson (private communication) 